\title{
Pelaksanaan Perawatan Pasien Berpusat pada Penurunan Tingkat Nyeri Post-Caesar
}

\author{
Muhammad Satya Arrif Zulhani ${ }^{1}$ Elsye Maria Rossa ${ }^{2}$ \\ Magister Manajemen Rumah Sakit, Pascasarjana, Universitas Muhammadiyah Yogyakarta ${ }^{1,2}$ \\ muhammadsatyaaz@gmail.com ${ }^{1}$
}

\begin{abstract}
Diajukan 7 Januari 2020 Diperbaiki 28 Januari 2020 Diterima 20 Februari 2020
ABSTRAK

Latar belakang: Angka sectio cesarea semakin hari semakin banyak, padahal tindakan operasi ini sebenarnya banyak menimbulkan dampak negatif bagi para wanita, salah satunya timbulnya nyeri pasca operasi. Nyeri dapat di-manage apabila ada komunikasi dan kerjasama yang baik antar petugas kesehatan. Patient Centered Care (PCC) merupakan sebuah pendekatan perawatan dengan meletakkan pasien berada ditengah perawatan, mengakomodasi keinginan dan kebutuhan pasien, serta untuk meminimalkan terjadinya ketidaksesuaian dalam sebuah perawatan. PCC secara fundamental dibangun dari sebuah kolaborasi interprofessional antara dokter, perawat, gizi, farmasi, rehabilitasi, dan lain-lain secara berkelanjutan.

Tujuan: Menilai implementasi PCC dalam menurunkan derajat nyeri pasien cesarea.

Metode: True Experiment dengan rancangan Post test only control group design. Responden berjumlah 44 orang, dibagi menjadi 22 orang untuk kelompok intervensi dan 22 orang untuk kelompok kontrol dimana sampel ini menggunakan metode Systematic random sampling. Pengukuran tingkat nyeri menggunakan Visual Analogue Scale(VAS).

Hasil: Uji Independent Sample T Test didapatkan ada perbedaan tingkat nyeri pada pasien pasca sectio cesarea antara kelompok intervensi dengan kelompok kontrol.

Kesimpulan: Implementasi Patient Centered Care (PCC) dapat menurunkan tingkat nyeri pada pasien pasca-sectio cesarea.
\end{abstract}

Kata Kunci: patient centered care; sectio cesarea; nyeri

\section{ABSTRACT}

Background: The number of cesarean sections is increasing regardless of the negative impact on women. One of the negative effects of cesarean section is postoperative pain. The pain can be managed through good communication and collaboration between health workers. Patient-Centered Care (PCC) is a treatment approach that accommodates the wants and needs of patients while minimizing the occurrence of care mismatches. PCC is fundamentally an ongoing interprofessional collaboration between doctors, nurses, nutrition, pharmacy, rehabilitation, and others.

Objective: Assessed the implementation of PCC in reducing the degree of pain in cesarean section patient.

with Posttest-only control group design. The research respondents consisted of 44 people (22 respondents in the intervention group and 22 respondents in the control group) who were obtained using the Systematic random sampling method. Measurement of the level of pain performed using the Visual Analogue Scale (VAS).

Results: Independent Sample T-Test showed that there were differences in the level of pain in post-cesarean section patients in the intervention group and the control group ( $p=0.028$ or $p<0.05)$.

Conclusion: Implementation of patient-centered care (PCC) can reduce the level of pain in post-cesarean section patients. 


\section{PENDAHULUAN}

Beberapa studi menunjukkan bahwa mortalitas dan morbiditas pada saat lahir dengan operasi caesar cukup tinggi. Hal ini dibuktikan dengan peningkatan rasio kematian dari 10 kematian / 100.000 kelahiran hidup (awal 90-an) ke 16 kematian / 100.000 kelahiran hidup (2006-2010) (Creanga et al., 2015). Durasi rawat inap untuk wanita yang menjalani operasi caesar secara signifikan lebih lama dibandingkan mereka yang melahirkan secara normal (Ghahiri et al. Khosravi, 2015). Sementara frekuensi seksio sesarea telah meningkat secara drastis di mana rata-rata setiap empat anak Eropa yang lahir dengan operasi caesar. Secara umum, ada 22,9 juta kelahiran caesar pada 2012(Martin et al., 2015).

Kemungkinan komplikasi pada operasi caesar lebih besar daripada persalinan fisiologis dan salah satunya adalah nyeri post operasi caesar. Rasa sakit tidak hanya akut, tetapi juga kronis yang dapat menyebabkan masalah pada 15,4\% (3-6 bulan), 11,5\% (6-12 bulan), dan 11,2\% (lebih dari 12 bulan) setelah operasi caesar (Weibel et al., 2016). Rasa sakit dapat menyebabkan ketidaknyamanan bagi pasien saat menyusui(Pratiwi, 2012).

Analisis multilevel telah mengonfirmasi bahwa tingkat manajemen kepuasan nyeri pasca-operasi dipengaruhi oleh pengalaman rasa sakit, keterlibatan pasien dalam memilih terapi, dan hubungan antara perawat dan pasien (Schwenkglenks et al., 2014). PatientCentered Care (PCC) adalah pendekatan pengobatan yang mengakomodasi keinginan dan kebutuhan pasien dan meminimalkan terjadinya ketidaksesuaian perawatan. PCC secara fundamental dibangun dari sebuah kolaborasi antar-profesional yang berkelanjutan antara dokter, perawat, gizi, farmasi, rehabilitasi, dll (Sidani and Fox, 2014). PCC diperlukan dalam memecahkan berbagai masalah di bidang pelayanan kesehatan. Ketidakpastian pasien dalam memilih pengobatan dapat diselesaikan melalui berbagi dan motivasi yang melibatkan tim pekerja kesehatan(Elwyn et al., 2014).

\section{METODE PENELITIAN}

Penelitian ini adalah penelitian studi kuantitatif dengan menggunakan desain True Experiment dan desain Post-test only control group. Penelitian ini membandingkan skor VAS dari kontrol dan kelompok perlakuan (treatment).

Penelitian ini dilakukan pada Desember 2018. Penelitian ini bertujuan untuk mengetahui pengaruh PCC pada tingkat rasa sakit pasca-operasi pada pasien operasi caesar di Rumah Sakit Panembahan Senopati Bantul. Pengambilan sampel dilakukan dengan menggunakan metode systematic random sampling dengan mengambil nomor genapganjil dari antrian pasien yang akan mendapatkan bedah sesar. Terdapat 44 responden, dibagi menjadi dua kelompok dimana setiap kelompok terdiri dari 22 responden.

Ada kriteria inklusi dan eksklusi yang digunakan untuk memaksimalkan objektivitas hasil penelitian. Kriteria inklusi adalah 1) responden pasien pasca-caesar, baik untuk pertama kalinya atau mereka yang telah melakukan caesar sebelumnya, 2) secara sadar menyatakan dan bisa diajak berkomunikasi, 3) bersedia menjadi responden, dan 4) setiap responden didampingi (minimal) satu anggota keluarga sedangkan kriteria eksklusi adalah 1) pasien dengan gangguan mental, 2) mengalami komplikasi pasca-bedah caesar, dan 3) pasien dengan kondisi tertentu yang dapat memperpanjang proses penyembuhan (diabetes mellitus atau hipertensi).

Kelompok intervensi atau pengobatan diberi pengarahan tentang deskripsi, manfaat, dan penerapan PCC. Tim PCC (dokter kandungan, ahli anestesi, perawat, bidan, dan apoteker) juga menerima modul PCC sebelum kunjungan tim. Intervensi dilakukan untuk sepanjang waktu pasien dirawat di rumah sakit selama sekitar 3 hingga 4 hari. Data menggunakan instrumen VAS yang dilakukan sehari setelah kunjungan tim (satu kali saja). Kelompok kontrol adalah tim lain yang tidak mendapatkan pengarahan implementasi PCC, 
metode pengumpulan data sama dengan kelompok intervensi. Semua data dikumpulkan oleh peneliti. Sebelum penelitian ini dilakukan, kami mendapatkan izin etik dari Komite Etik Universitas Muhammadiyah Yogyakarta.

\section{HASIL}

Tabel 1. Jumlah Tenaga Kesehatan Di Bangsal Alamanda

\begin{tabular}{clc}
\hline No & \multicolumn{1}{c}{ Tenaga } & Jumlah \\
\hline 1 & Obstetri dan & \\
& $\begin{array}{l}\text { Ginekologi } \\
\text { Spesialis }\end{array}$ & 3 \\
2 & Obgyn Resident & 1 \\
3 & Ward Kepala & 1 \\
4 & Perawat dan & 28 \\
& Bidan & 1 \\
5 & Perawat Asisten & 2 \\
6 & Staf administrasi & \\
\hline
\end{tabular}

Tabel 1 menunjukkan 29 pekerja kesehatan di bangsal Alamanda (kebidanan dan kandungan bangsal).

Tabel 2. Karakteristik Responden

\begin{tabular}{clll}
\hline No & \multicolumn{1}{c}{$\begin{array}{c}\text { Karakteristik } \\
\text { Responden }\end{array}$} & $\begin{array}{c}\text { Kelompok } \\
\text { Perlakuan } \\
\mathbf{f}(\%)\end{array}$ & $\begin{array}{c}\text { Kelompo } \\
\mathbf{k} \\
\text { Kontrol } \\
\mathbf{f}(\%)\end{array}$ \\
\hline $\mathbf{1}$ & Usia & & \\
2 & berusia $<20$ tahun & $3(13,6)$ & $4(18,2)$ \\
3 & 30 tahun - 21 & $13(59.1)$ & $11(50)$ \\
4 & 40 tahun - 30 & $4(18,2)$ & $5(22,7)$ \\
5 & berusia> 40 tahun & $2(9.1)$ & $2(9.1)$ \\
6 & Kehamilan & & \\
7 & G1 & $10(45,4)$ & $8(36,4)$ \\
8 & G2 & $6(27,3)$ & $6(27,3)$ \\
9 & G3 & $3(13,6)$ & $4(18,2)$ \\
10 & G4 & $1(4.5)$ & $3(13,6)$ \\
11 & G5 & $2(9.1)$ & $1(4.5)$ \\
$\mathbf{1 2}$ & Pendidikan & & $3(9.1)$ \\
13 & Lulusan Sekolah dasar & $1(4.5)$ & $7(22,7)$ \\
14 & Lulusan SMP & $8(36,4)$ & $8(36,4)$ \\
15 & Lulusan SMA & $9(40,9)$ & $4(18,2)$ \\
\hline 16 & Bujangan & $4(18,2)$ & \\
\hline
\end{tabular}

Tabel 2 menunjukkan usia, kehamilan, dan pendidikan responden. Hasil tes SPSS pada skor sakit dan usia yaitu 0,757 , rasa sakit dan riwayat kehamilan adalah 0,792 , dan rasa sakit dan riawayat pendidikan sebesar 0,645. Responden yang memiliki skor $>0,05$ dapat dikatakan bahwa tidak ada korelasi antara rasa sakit, usia, kehamilan, dan pendidikan.

Tabel 3. Skor VAS Terendah dan Tertinggi

\begin{tabular}{|c|c|c|}
\hline & $\begin{array}{l}\text { skor } \\
\text { terendah }\end{array}$ & $\begin{array}{l}\text { skor } \\
\text { tertinggi }\end{array}$ \\
\hline $\begin{array}{l}\text { kelompok } \\
\text { perlakuan }\end{array}$ & 2 & 7 \\
\hline $\begin{array}{l}\text { kelompok } \\
\text { kontrol }\end{array}$ & 2 & 8 \\
\hline
\end{tabular}

Tabel 3 menunjukkan skor VAS terendah dan tertinggi. Minimum skor VAS dari kelompok intervensi adalah 2, sedangkan nilai tertinggi adalah 7. Pada kelompok kontrol, skor terendah VAS adalah 2, sedangkan nilai tertinggi adalah 8

Tabel 4. Hasil uji statistik yang berbeda

\begin{tabular}{lccc}
\hline & $\begin{array}{c}\text { Kelompok } \\
\text { Perlakuan }\end{array}$ & $\begin{array}{c}\text { Kelompok } \\
\text { Kontrol }\end{array}$ & $\begin{array}{c}\boldsymbol{p} \\
\text { Skor }\end{array}$ \\
\hline Nilai & & & 0,02 \\
VAS & 4.68 & 5.32 & 8 \\
\hline
\end{tabular}

Tabel 4 menunjukkan hasil tes statistik yang berbeda. Uji normalitas data menggunakan Kolmogorov Smirnov menunjukkan bahwa data terdistribusi secara normal dengan skor sig 0,42 $(>0,05)$. Hasil Independent Sample T-Test menunjukkan bahwa ada perbedaan tingkat nyeri antara pasien di bagian pasca-caesar pada kelompok PCC (kelompok perlakuan) dan mereka yang tidak PCC (kelompok kontrol). Ini berarti bahwa $\mathrm{H}_{0}$ diterima.

\section{PEMBAHASAN}

Pengaruh Umur, Sejarah Kehamilan, dan Pendidikan pada Tingkat Nyeri Pasien PascaCaesar

Mayoritas responden dalam penelitian ini berusia 21-30 tahun. Berdasarkan riwayat kehamilan, besar responden adalah G1 atau kehamilan pertama. Sementara itu, berdasarkan riwayat pendidikan, mayoritas responden lulusan SMA (17 responden). Namun, hasil crosstab antara skor nyeri dengan usia, riawayat kehamilan, dan riawayat pendidikan menunjukkan hasil yang tidak signifikan $(>0,05)$ sehingga dapat dikatakan 
bahwa usia, riwayat kehamilan, dan pendidikan tidak terkait dengan skor nyeri.

Dalam studi dari operasi hernia, disebutkan bahwa pasien anak muda lebih mungkin untuk mengalami sakit kronis pascaoperasi inguinal (CPIP) atau nyeri pascaoperasi kronis (Langeveld et al., 2015). Hasil ini bertentangan dengan hasil penelitian ini, dimana usia tidak secara signifikan mempengaruhi nyeri.

Sementara itu, riwayat kelahiran (paritas) atau kehamilan dalam penelitian ini didukung oleh penelitian yang dilakukan oleh Pereira et al. (2017) yang menyatakan bahwa tidak ada hubungan yang signifikan antara paritas dengan keterbatasan fungsional dan nyeri pada pasien postpartum.

Februanti et al. (2019) menyatakan bahwa pendidikan dan pekerjaan tidak berhubungan dengan kemampuan pasien pasca-caesar saat menyusui. Menyusui dipengaruhi oleh faktor emosional dan kenyamanan. Oleh karena itu, tingkat pendidikan tidak memiliki pengaruh yang signifikan pada skor nyeri.

\section{Tingkat Nyeri Pada Perlakuan dan Kelompok Kontrol}

Visual Analog Scale (VAS) sering digunakan dalam beberapa penelitian untuk mengukur tingkat rasa sakit. Myles et al. (2017) menyatakan bahwa bedah caesar adalah operasi besar. Penelitiannya menemukan nilai rata-rata pada hari pertama kunjungan adalah 19 (bedah minor), 29 (operasi menengah), dan 34 (operasi besar). Antara 0-100, skor caesarean section adalah 37. Di sisi lain, nilai terendah untuk dua kelompok dalam penelitian ini adalah 2, sedangkan nilai tertinggi untuk kelompok perlakuan adalah 7 dan 8 untuk kelompok kontrol. Hasil ini tidak berbeda secara signifikan dari hasil penelitian sebelumnya.

Penelitian lain yang menggunakan VAS menunjukkan bahwa perempuan lebih mungkin untuk merasakan sakit daripada pria. Ini berarti bahwa persiapan pra-operasi yang baik dapat meminimalkan gejala sakit pascaoperasi (Sadaf and Ahmad, 2014).

\section{Pengaruh Patient-Centered Care pada Tingkat Rasa Sakit}

Hasil sig menunjukkan bahwa $<0.05$, sehingga dapat dikatakan bahwa pasien yang menggunakan PCC dapat menurunkan level kesakitan dalam kasus pasien post-cesarea. Penelitian ini sejalan dengan penelitian yang dilakukan Chieng, Chan, Klainin-Yobas, and He (2014) yang menunjukkan bahwa persiapan sebelum operasi (sepeti dukungan emosional, kenyamanan fisik, informasi dan edukasi pelaksanaan) akan meningkatkan hasil yang bervariasi pada usia yang berbeda-beda.

Pembentukan tim kesehatan yang solid juga agak sulit dilakukan. Bernhofer and Sorrell (2015) menyatakan bahwa permasalahan komunikasi dan kurangnya edukasi tentang rasa sakit pasca-operasi akan memengaruhi dalam manajemen rasa sakit seorang pasien. Maka solusi yang tepat untuk masalah ini adalah PCC

Taplin et al., (2015) menyatakan bahwa tim asuhan multidisiplin (MDT) mampu meningkatkan hasil (outcome) pasien (termasuk pasien dengan perawatan paliatif), mengurangi durasi rawat inap, dan meningkatkan kualitas hidup pasien dengan kanker. Namun PCC mengutamakan keterlibatan pasien dalam perawatan, sementara MDT hanya menempatkan pasien sebagai objek perawatan.

PCC juga memiliki dampak positif pada departemen bedah ortopedi di sebuah rumah sakit di Amerika. Penelitian kohort dilakukan pada pasien studi yang terlibat rata-rata osteoarthritis, disc hernia, stenosis tulang belakang, dan patah tulang. Sama seperti PCC, studi ini juga menggunakan Shared Decision Making (SDM) dimana pengambilan keputusan melibatkan petugas kesehatan dan pasien. Metode SDM memastikan bahwa pasien menerima informasi tentang kondisinya dan mendapat intervensi sesuai dengan kebutuhan pasien dan kenyamanan. Penelitian ini menggunakan parameter Quality of Life (QoL) dan survei pengetahuan pasien penyakit mereka(Sepucha et al., 2018). 
Dukungan emosional dan kontrol ketakutan dan kecemasan merupakan bagian dari 8 dimensi PCC yang bertujuan untuk menghilangkan rasa sakit pasca-operasi dan meningkatkan hasil pasien. Ali et al. (2014) menyatakan bahwa kecemasan mempengaruhi hasil pasien pasca-operasi. Tingkat kecemasan yang rendah akan mengurangi skor VAS, jumlah pasien rawat inap dan mengurangi jumlah penggunaan analgesik.

Aziato and Adejumo (2014) menyatakan bahwa kombinasi dari kerja sama tim, komunikasi, hubungan interpersonal, pemahaman, apresiasi, dan fleksibilitas meningkatkan hasil (outcome) pasien dan mengurangi kemungkinan nyeri post operative pain (POP).

Dalam studi lain di bidang bedah ortopedi menyatakan bahwa peningkatan mutu berkelanjutan (Continuous Quality Improvement / CQI) dapat meningkatkan kualitas manajemen nyeri. Strategi CQI adalah penilaian ulang dan analisis manajemen rasa sakit melalui kerja sama tim dan pendidikan bagi tenaga kesehatan. Total Hip Arthroplasty (THA) pasien yang terlibat dalam penelitian ini juga menunjukkan kepuasan meningkat (Benditz et al., 2016).

\section{KESIMPULAN}

Kesimpulan dari penelitian ini adalah:

1. Pelaksanaan Patient-Centered Care (PCC) dapat mengurangi tingkat nyeri pada pasien bagian pasca-caesar.

2. Tidak ada hubungan antara skor nyeri dengan usia, riwayat kehamilan, dan pendidikan.

Beberapa saran yang disampaikan oleh peneliti adalah sebagai berikut:

1. Untuk rumah sakit

Rumah sakit harus menerapkan PCC untuk semua pasien karena PCC memiliki dampak positif pada pasien, tenaga kesehatan, dan rumah sakit.

2. Untuk peneliti selanjutnya

Gunakan metode campuran untuk mendapatkan hasil yang maksimal dan lebih objektif.

\section{DAFTAR PUSTAKA}

Ali, A., Altun, D., Oguz, B.H., Ilhan, M., Demircan, F., Koltka, K., 2014. The effect of preoperative anxiety on postoperative analgesia and anesthesia recovery in patients undergoing laparascopic cholecystectomy. J. Anesth. 28, 222-227. https://doi.org/10.1007/s00540-013-1712$\underline{7}$

Aziato, L., Adejumo, O., 2014. The Ghanaian Surgical Nurse and Postoperative Pain Management: A Clinical Ethnographic Insight. Pain Manag. Nurs. 15, 265-272. https://doi.org/10.1016/j.pmn.2012.10.002 Benditz, A., Greimel, F., Auer, P., Zeman, F., Göttermann, A., Grifka, J., Meissner, W., von Kunow, F., 2016. Can consistent benchmarking within a standardized pain management concept decrease postoperative pain after total hip arthroplasty? A prospective cohort study including 367 patients. J. Pain Res. 9, $\begin{array}{lllllllll}1 & 2 & 0 & 5 & - & 1 & 2 & 1 & 3\end{array}$. https://doi.org/10.2147/JPR.S124379

Bernhofer, E.I., Sorrell, J.M., 2015. Nurses Managing Patients' Pain May Experience Moral Distress. Clin. Nurs. Res. 24, $\begin{array}{llllllll}4 & 0 & 1 & - & 4 & 1 & 4\end{array}$. https://doi.org/10.1177/105477381453312 $\underline{4}$

Chieng, Y.J.S., Chan, W.C.S., Klainin-Yobas, P., He, H.-G., 2014. Perioperative anxiety and postoperative pain in children and adolescents undergoing elective surgical procedures: a quantitative systematic review [WWW Document]. J. Adv. Nurs. https://doi.org/10.1111/jan.12205

Creanga, A.A., Berg, C.J., Syverson, C., Seed, K., Bruce, F.C., Callaghan, W.M., 2015. Pregnancy-Related Mortality in the United Stated, 2006-2010. Obstet. G y n e c o 1 . 125 , 5 . https://doi.org/10.1097/AOG.0000000000 $\underline{000564}$ 
Elwyn, G., Dehlendorf, C., Epstein, R.M., Marrin, K., White, J., Frosch, D.L., 2014. Shared Decision Making and Motivational Interviewing: Achieving Patient-Centered Care Across the Spectrum of Health Care Problems. Ann. F a m . M e d . 12, $270-275$. https://doi.org/10.1370/afm.1615

Februanti, S., Hartono, D., Kartilah, T., 2019. Relationship Between Post Cesarean Section Characteristics With Exclusive Breastmilk Giving In Tasikmalaya Indonesia. Presented at the $1 \mathrm{st}$ International Conference on InterProfessional Health Collaboration (ICIHC 2018), Atlantis Press. https://doi.org/10.2991/icihc-18.2019.75

Ghahiri, A., Khosravi, M., 2015. Maternal and neonatal morbidity and mortality rate in caesarean section and vaginal delivery. A d v . B i o m e d. R e s . 4 . https://doi.org/10.4103/2277-9175.166154

Langeveld, H.R., Klitsie, P., Smedinga, H., Eker, H., van't Riet, M., Weidema, W., Vergouwe, Y., Bonjer, H.J., Jeekel, J., Lange, J.F., 2015. Prognostic score of age for chronic postoperative inguinal pain. $\mathrm{H}$ e r n i a $19,549-555$. https://doi.org/10.1007/s10029-014-1282$\underline{0}$

Martin, J.A., Hamilton, B.E., Osterman, M.J., Curtin, S.C., Matthews, T.J., 2015. Births: final data for 2013. Natl. Vital Stat. Rep. Cent. Dis. Control Prev. Natl. Cent. Health Stat. Natl. Vital Stat. Syst. 64, 1-65.

Myles, P.S., Myles, D.B., Galagher, W., Boyd, D., Chew, C., MacDonald, N., Dennis, A., 2017. Measuring acute postoperative pain using the visual analog scale: the minimal clinically important difference and patient acceptable symptom stated. BJA Br. J. An aesth. 118, 424-429. https://doi.org/10.1093/bja/aew466

Pereira, T.R.C., Souza, F.G.D., Beleza, A.C.S., 2017. Implications of pain in functional activities in immediate postpartum period according to the mode of delivery and parity: an observational study. Braz. J . P h y s. The r . 21, 3 7-43 . https://doi.org/10.1016/j.bjpt.2016.12.003

Pratiwi, R., 2012. Penurunan Intensitas Pain Akibat Luka Post Cesarean Section Setelah Dilakukan Latihan Teknik Relaksasi Pernapasan Menggunakan Aromaterapi Lavender Di Rumah Sakit Al Islam Bandung. Stud. E-J. 1, 30.

Sadaf, D., Ahmad, M.Z., 2014. Factors Associated with Postoperative Pain in Endodontic Therapy. Int. J. Biomed. Sci. IJBS 10, 243-247.

Schwenkglenks, M., Gerbershagen, H.J., Taylor, R.S., Pogatzki-Zahn, E., Komann, M., Rothaug, J., Volk, T., Yahiaoui-Doktor, M., Zaslansky, R., Brill, S., Ullrich, K., Gordon, D.B., Meissner, W., 2014. Correlates of satisfaction with pain treatment in the acute postoperative period: Results from the international PAIN OUT registry. PAIN® 155, $\begin{array}{llllllllll}1 & 4 & 0 & 1 & - & 1 & 4 & 1 & 1\end{array}$. https://doi.org/10.1016/j.pain.2014.04.021 Sepucha, K.R., Atlas, S.J., Chang, Y., Freiberg, A., Malchau, H., Mangla, M., Rubash, H., Simmons, L.H., Cha, T., 2018. Informed, Patient-Centered Decisions Associated with Better Health Outcomes in Orthopedics: Prospective Cohort Study. Med. Decis. Making 38, 1018-1026. https://doi.org/10.1177/0272989X1880130 $\underline{8}$

Sidani, S., Fox, M., 2014. Patient-centered care: clarification of its specific elements to facilitate interprofessional care. J. Interprof. Care 28, 134-141. https://doi.org/10.3109/13561820.2013.86 $\underline{2519}$

Taplin, S.H., Weaver, S., Salas, E., Chollette, V., Edwards, H.M., Bruinooge, S.S., Kosty, M.P., 2015. Reviewing Cancer Care Team Effectiveness. J. Oncol. Pract. https://doi.org/10.1200/JOP.2014.003350

Weibel, S., Neubert, K., Jelting, Y., Meissner, W., Wöckel, A., Roewer, N., Kranke, P., 2016. Incidence and severity of chronic pain 
Pelaksanaan Perawatan Pasien Berpusat pada Penurunan Tingkat Nyeri...

after caesarean section: A systematic https://doi.org/10.1097/EJA.00000000000 review with meta-analysis. Eur. J. $\underline{00535}$

Anaesthesiol. EJA 33,853. 